\title{
Turing Machine as an ecological model \\ for Task Analysis
}

Thierry Morineau, Emmanuel Frénod, Caroline Blanche, and Laurence Tobin,

\author{
University of Southern Brittany \\ Centre Yves Coppens, Campus de Tohannic \\ F-56000 Vannes, France. \\ Tel.: $33(0) 297017137$ \\ Fax.: $33(0) 297017071$ \\ E.mail: thierry.morineau@univ-ubs.fr
}




\begin{abstract}
:
We present a new model for task analysis based on the ecological approach initiated by Cognitive Work Analysis (CWA). This model aims to improve the implementation of the theoretical principles involved in the ecological approach of a work system. More precisely, under current CWA, task analysis uses Rasmussen's ladder. However, this approach fails to highlight the contextual constraints on the task. Our model is based on the Turing Machine formalism and takes into account the variety of situations that can be experienced by an agent, and especially degraded situations of work. Moreover, it can model the concept of affordancespecifying information. We show that this formalism can be applied to a prototypical task like opening a door.
\end{abstract}

Keywords: Cognitive work analysis, task analysis, Turing machine, affordance 


\section{Introduction}

In ergonomics and engineering, task analysis is a critical stage in the description of a work system. Its aim is to oversee what information needs to be processed by operators and what kind of operations need to be performed in order to control the work system. Numerous methods have been proposed in the literature (for a review see Stanton et al., 2005). These task analysis methods fall into two main categories (Bainbridge, 1997), sequential and contextual approaches. In the sequential approach the task is considered as a sequence of processing stages that must be respected by the operator. The contextual approach leads to perceive task as a choice among several processes according to a context.

The sequential approach in task analysis usually considers task either as a goal oriented hierarchical network, in which an overall goal can be reached by going through the process of subgoals or actions (Hierarchical Task Analysis - HTA, Annett, 2004; Goal Operator Method Selection - GOMS, Kieras, 1997), or as a set of cognitive stages that must be serially processed (Norman, 1988; Rasmussen 1986). Several limits of the sequential model of the task --lack of flexibility to retrace the degrees of freedom available to the operator, lack of sensitivity as regards contextual constraints-- led to the development of contextual models of the task (Critical Decision Method, Klein and Armstrong, 2004; Suchman, 1987; Cognitive Work Analysis, Vicente, 1999). Contextual models suggest that, in the scope of a task, the operator activates cognitive resources to cope with constraints from the work environment, without a predetermined specific sequence for resources activation.

This contextual approach is particularly highlighted in the theoretical postulates of Cognitive Work Analysis (CWA) proposed by Vicente (1999). In CWA, work constraints are qualified as ecological since they refer to demands coming from the work domain requiring an adaptation from operators. Ecological constraints shape the kind of task that can be performed, the strategies, the tools to use, the organisational modalities of work, and finally the cognitive processes that must be engaged by operators. The first step of CWA is Work Domain Analysis (WDA), which constitutes the foundation on which it is developed (see Vicente, 2002; Burns 
and Hadjuckewicz, 2004 for a review). The second step of CWA concerns task analysis, and has received relatively less theoretical specification. Even though specific techniques and methods are not advocated for CWA, Rasmussen (1986) suggested using a sequential task model: the decision ladder (see for instance Dominguez, 1997; Naikar, 2006). To cope with drawbacks due to the sequential character of the decision ladder model, significant nuances were introduced by Rasmussen (1986). One such nuance is shortcuts in task processing. The observation of a relevant fact for instance, can directly lead to the activation of a procedure. Another variation is that information processing can be initiated at any one of the cognitive steps and does not necessarily finish with execution. Also, Rasmussen declared that the model was a mere template for the description of information processing which could deviate from this rigid sequence. But despite this added flexibility, the decision ladder does not really fit in a contextual approach (Baindbridge, 1997; Vicente, 1999). Particularly, CWA implies that ecological constraints of the domain be gradually replaced by cognitive constraints, whereas the architecture of the decision ladder is only based on specifications coming from the cognitive constraints. For Rasmussen et al. (1994), and Vicente and Rasmussen (1990), the work domain can be viewed as man-made ecology composed of a hierarchy of affordances described through the WDA. The concept of affordance which brings in a continuous link between ecological and cognitive constraints (Gibson, 1979) cannot be directly retrieved within the Rasmussen's ladder.

\section{INSERT FIGURE 1}

The purpose of this paper is to present a task model bridging the contextual and cognitive constraints involved in the task through the concepts of affordance and affordancespecifying information. Our model is based on the Turing Machine formalism, which has been proposed by Wells (2002) to model affordances and cited by Bubb (2006) as a fitting model for work analysis.

In the next section, we will present the formalism of the Turing Machine and its use for modelling affordance and affordance-specifying information. Section 3 presents the principles 
of a task analysis by Turing Machine. Section 4 concerns the application to an elementary domain (a door system) and its comparison with a sequential approach through the HTA method. Section 5 discusses this methodological proposal.

2. Turing Machine Formalism and its application to affordance, and affordance-specifying information modelling

\subsection{Turing Machine principles}

Turing $(1936,1937)$ notes that every calculus can be performed with the help of a paper tape composed of an infinite number of squares. In each square, the calculator agent is able to write a symbol chosen from a finite set of symbols, for example $\{0,1, \#\}$. At any time, the action of the calculator agent is a consequence of the symbols observed on the paper tape and of its "mental state". Like the symbol number, the number of possible mental states is finite. Each operation of the agent modifies the system composed by the agent and the paper tape on the scale of a given square. The elementary operations can be:

1. Read the symbol in the observed square (reading);

2. Replace the symbol read in the observed square (transformation);

3. Move the tape to the left or the right side, to the next square (movement);

4. Change in the mental state of the agent (change of state).

In this framework, a configuration of a Turing Machine is defined as a value of the couple (mental state, information on the paper tape).

\subsection{Turing Machine configuration, affordance and affordance-specifying information}

Traditionally, Turing Machine architecture has been interpreted by symbolic systems theorists as reflecting internal symbolic processing. Alternatively, Wells $(1998,2002)$ and some computer scientists (de Oliveira et al., 2001) proposed that Turing Machine architecture refers to organism-environment interaction. Information inputs coming from the paper tape depends on the external environment, whilst the control architecture (writing, mental state, reading and movement of the paper tape) reflects the activity of the organism. 
Wells (2002) used the notion of configuration described above to define the notion of affordance. An affordance would be the interaction between information coming from the environment and the current mental state of the agent. Recently, this formalism was applied to a realistic situation of predation behaviour performed by an elementary animal (Morineau and Frénod, 2005). This last research showed that information read on the tape by an agent can be considered as patterns of affordance-specifying information, rather than as affordance per se. Whereas affordances exist independently in the environment, affordance-specifying information is picked up by the agent depending on its current mental state. This distinction was also introduced by Gaver (1991; see also McGrenere and Ho, 2000) to explain the possibility of hidden affordance or false affordance emerging from the incompatibility between affordance and information captured by the agent.

\section{Turing Machine Task Analysis (TMTA)}

According to Bubb (2006), work can be viewed as change of information. Information embedded in the work domain are read and modified by the action performed by the operator. This process can be considered as a Turing Machine process through which an agent produces a new order in information. Figure 2 shows the set up of a Turing Machine Task Analysis. This Turing Machine is composed of an agent that captures patterns of information coming from the affordances embedded in the work domain. This work domain is described through a matrix dividing the domain by system, subsystem and component and describing it through five functional points of view. The agent can operate on the domain through objective transformation, movements and change of mental state. These changes of mental state correspond to a mental navigation in the work domain through internal knowledge, or change of viewpoint on the environment.

\section{INSERT FIGURE 2}


To model a task in this manner, TMTA needs to describe firstly, the work domain secondly, patterns of information coming from the domain and thirdly, the operations done by the agent to change the patterns of information in order to achieve a general goal.

\subsection{The preliminary Work Domain Analysis}

Following Rasmussen et al. (1994), and Vicente and Rasmussen (1990), we shall consider that the functions described in the WDA represent a hierarchy of affordances. To describe these functions, CWA proposes two dimensions: the Abstraction Hierarchy (AH) and the Part-Whole Hierarchy (PWH). The Abstraction Hierarchy (AH) captures the means-ends relationship between different functional descriptions of the domain. The lower levels of the hierarchy are concrete descriptions of the domain components and the higher levels are abstract descriptions of the same domain. Five levels of functionalities are described: physical forms (location \& appearance of objects), physical functions (functions associated with these objects), processes (processes in which the objects are implemented), abstract functions (laws and principles driving the subsequent processes), and general purposes (the fundamental purposes justifying the presence of the work system). The second dimension describes the domain through a structural decomposition or "Part-Whole" Hierarchy (PWH). The work domain is decomposed in aggregated entities, called subsystems and components.

\subsection{Patterns of information coming from the work domain}

In articulation with the WDA, we propose to add a description of the set of patterns of information that can be picked up from the work domain by an agent. We consider that a pattern of information is composed of information coming from the cells of the AH/PWH matrix. Each information can take a value between $[0,1, \#]$ according to its relevance for the current task. At the cell level, if the information fulfils the task goal, then it takes the value [1], otherwise 0 . The value $[\#]$ means a lack of information perceived as relevant for the task.

A first purpose of the TMTA is to assess the different patterns of information that can come from the domain. If we consider that the agent can perceive the domain through only one 
level of abstraction at a given moment, then the number of possible patterns of information would be $n^{3}$, with $n$ is the number of entities decomposed in the Part-Whole Hierarchy and 3, the number of possible values $(0,1$ or \#). This first step of task modelling gives the opportunity to highlight some contexts of work that can be considered as degraded. For instance, the pattern of information presented in table 1 shows a degraded work situation in a nuclear plant. At a given level of abstraction of the Abstraction Hierarchy, the system "water network" provides the information that a flow of water is on (value: 1), the subsystem "Valve" and its component "valve command" gives the information at their levels that they are closed (value: 0). Such an inherently contradictory pattern of information has been experienced by operators during the accident of the nuclear plant "Three Mile Island" (Burns and Hajduckiewicz, 2004).

\section{INSERT TABLE 1}

The exhaustive analysis of patterns of information coming from the domain should make it possible to envisage what context of work can be represented by each pattern and what operations must be engaged by the operator to cope with the context. These operations would consist in performing transformation(s) on the work domain, mentally navigating in the Abstraction Hierarchy for a better understanding of the situation and/or performing movement(s) to control the situation.

\subsection{TMTA analysis of agent's operation to change work patterns of information}

We can consider that controlling the work situation consists in making change in the value of the information coming from the domain (Bubb, 2006). Three kinds of information changes can potentially be modelled in parallel through Turing Machine analysis: transformation, change in mental state, and movement.

- Transformation: It describes how the agent performs actual changes on the object of the work domain. It corresponds to writing on the paper tape in the Turing Machine formalism. It leads to concrete modification of the domain objects in order to attain the goal of the task. This 
operation leads to giving the value [1] to information associated to the domain object concerned. A transformation modifies the state of an object of work, like cutting a piece of paper or locking a system. It leaves a print of the agent onto the environment.

- Change of mental state: The modification of an information value coming from the work domain can also be the result of a change of mind for the agent. This change allows for the cognitive reframing of the interaction experienced with the work domain by perceiving it from another point of view. Information that can have the value " 0 " at the physical function level could take the value "1", strictly because the agent has navigated toward another level, like the process level. Researches using the Cognitive Work Analysis framework showed that operators mentally navigate through the Abstraction Hierarchy (Vicente, 2002; Vicente, Christoffersen, and Pereklita, 1995). When the agent does not find the information enabling him/her to progress in the task, a change of abstraction level occurs. For instance in degraded situation, to improve the understanding of the situation, such a change of level would mean rising through the Abstraction Hierarchy (Rasmussen, 1986). Conversely, anticipatory and planning activities lead the agent to go from high abstract level to more concrete level (Vicente, Christoffersen, and Pereklita, 1995).

To simplify the model, we will consider that this mental navigation is made simultaneously through all the components of the Part-Whole Hierarchy at a given level of the Abstraction Hierarchy. A mental state is characterized by the functional level in the AH to which it refers or by a mental state $H$, which is an exit of the domain caused by task success or renunciation.

- Movement of the agent in the environment: To change information value, the agent can perform movements applied on the domain objects. In the Turing Machine formalism, it corresponds to moving the paper tape. These movements concerns spatial change in the position of objects. Ego-centred movements can also be modelled by this manner (e.g. agent's locomotion).

Note that the degrees of reversibility of these three kinds of operations on the objects of the domain differ. Change of mental state is the more reversible operation, followed respectively by movements and transformation on objects. In addition, note that the operation of reading the 
paper tape in Turing formalism is always implicitly present through the perception of patterns of information

\section{Example of application: the door use}

The use of a door is typically used to explain the concept of affordance in ergonomics (Gaver, 1991; Norman, 1988). Some doors provide visual cues given by the shape of the handle that are incompatible with the actual direction of movement needed (pull or push). In the next sections, we present the stages of a TMTA: the work domain analysis, patterns of information and their potentials meanings, and the simulation of an interaction with a particular door system. Finally, we propose a comparison between the TMTA and a classical sequential analysis with the HTA technique (Chang \& Drury, 2007).

\subsection{Work Domain Analysis of door system}

We suggest that a door system is composed of subsystems: the door frame, and one or several door leaves. The leaf subsystems are composed of the locking and handle components. Our functional model (Abstract Hierarchy) is partly based on the recent classification made by Chang and Drury (2007).

\section{INSERT TABLE 2}

In our analysis (see table 2), we focused on the leaf subsystem as sufficient to allow the functioning of the system. The door presents a general functional purpose of closing and opening an entry. The door components are governed by laws of physics, mechanics, and sometimes automatics (in the case of automatically controlled doors). The leaf component specifically involves the laws of entropy which concern the air and substance exchanges that the door can prevent (fire and smoke diffusion for instance). The handle component is specified by ergonomic principles defining the way to open the door. The locking component depends on material or data coding laws depending on the locking process (key or automation). 
The processes level of $\mathrm{AH}$ describes the door system through operating processes engaged to operate the leaf, handle and locking components. The processes are based on physical functions, i.e. equipment and features physically defining the door system. These devices are concretely available in an environment through locations and appearances as a physical form level of the Abstraction Hierarchy.

\subsection{Analysis of patterns of information coming from door system}

While sequential models of task focus on the hierarchies of goals or cognitive stages, TMTA rather analyses the meaning embedded in patterns of information specifying affordances coming from the work domain. Firstly, this approach requires taking into account all the patterns of information from the domain. In this example of the door system, we took into account the patterns of information constituted of one bit of information ( 0 or 1 value), and a specific pattern where no relevant information is displayed by the overall door system (symbol \#). It means $2^{3}=8+1=9$ patterns of information.

\section{INSERT TABLE 3}

Secondly, we listed the meanings that each pattern of information can bring whether work situation is degraded or not (see Table 3). We notice that degraded situations can be caused by different contingencies: the door is hidden (hidden affordance), a lack of success in agent's operations, or functional problems like wood swelling, leaf barred, or false information coming from a device (false affordance). Note that situations S5, S6 and S7 are strictly deficient. Components information (handle or lock) are in contradiction with information provided by the system from which they depend (the leaf subsystem). As can be seen in table 3 , the perception of degraded situations can require a certain level of understanding that can be obtained by reaching more abstract levels in the $\mathrm{AH}$.

To observe the impact of contingencies on the interpretation of the domain information by the agent, one can simulate a concrete interaction with a door through the TMTA. 


\section{3. Simulation of a typical problem in door task control}

The task simulated consists of a door in a corridor. The door is composed of a leaf with a single vertical handle suggesting pulling for opening. However, the door requires a push action (Figure 3). We describe below a typical, but fictive sequence of task control on this kind of door with the Turing Machine operations involved (reading of patterns of information, transformation, change of mental state, movement). Note that for each next mental state, we propose a query that justifies the navigation through mental states (Table 4). The agent is not necessarily conscious of the queries. They can be implicitly embedded in the movements or transformations.

\section{INSERT FIGURE 3}

INSERT TABLE 4

\section{Stage 1: In front of the door}

In front of the door, the agent discovers the positions and forms of the door components. We suppose that the agent infers on the basis of door appearances (Physical Forms), that the lock function is activated. The handle and leaf devices yield information that the door system is closed (reading on the paper tape: $0,0,0$ ).The agent's mental state stands at the level of physical forms in the AH (no change in Turing Machine state). The agent continues the approach on the door system (movement).

\section{Stage 2: To open the locking system}

At this stage (reading: \#, 0,\#), the agent has to solve a micro-problem that corresponds to the transformation of the state of the lock (transformation), through a hand rotation (movement). This situation leads the agent to rise in the AH through querying if the key component will work (change of state). 
Stage 3: The locking system is open, the handle can be used.

Since the locking system has functioned well (reading: $0,1,0$ ), the agent stands in the same mental state (physical function) and focuses on the handle physical function that affords the user to pull it (movement: to pull on the handle).

Stage 4: Despite the pull action, the handle does not work

The pull action does not enable to open the door (reading: $0,1,0$ ). This problem leads the agent to go towards the higher AH level to understand the situation (Processes level change of state). This mental navigation is done through the question "Is the effort generated sufficient to open the door?" The agent tries to answer this question through a stronger pulling action (movement to test the process).

Stage 5: Despite the stronger pulling action, the handle still does not work

The door stands in the same state (reading: $0,1,0$ ). This situation requires navigating to the Abstract Function level, which corresponds to knowledge of the laws of door functioning (change of state). This frame of perception allows the agent to attempt to push the handle (movement to test another law that can govern the door).

Stage 6: The handle and the locking component are in states satisfying the opening of the leaf

Since the handle shows an efficient behaviour (reading: $0,1,1$ ), the agent stands at the same mental state and interrogates the law of functioning of the leaf. "Will the leaf follow the handle behaviour?" The answer will be given through the continuous movement of the leaf with the handle. Note that this stage will certainly last a very short time.

Stage 7: The door is finally open.

The reading of the pattern of information: " $1,1,1$ " in this last mental state at the Abstraction Function level will lead to consider this door has a counter-intuitive system. This conclusion could be eventually stored in memory to warn the agent of this degraded situation. But this later cognitive process goes out of a task analysis based on affordance. The completion of the task leads the agent to go toward another task (movement) through the mental state $\mathrm{H}$. 


\subsection{Comparison between TMTA and Hierarchical Task Analysis of door use}

Chang and Drury (2007) also made a task analysis of the use of a hinged door (figure 4). The technique used was the Hierarchical Task Analysis, which can be classified as a sequential model of task based on a hierarchical network of goal and means-end relationship (HTA - Shepherd, 2001; Miller and Vicente, 2001). In brief, the main goals described are: detect door and people, approach, evaluate situation (make a decision), interact with people and door, leave doorway. This model corresponds to a rational use of the door in the scope of the problem-solving paradigm. The door use is described within a cognitive sequence that is closed to the cognitive steps involved in the Rasmussen's decision ladder (perception, evaluationdecision and action). But nothing leads to suppose that people follow this normative model to perform such a routine task. Our TMTA model does not impose such cognitive procedure. The user is in a given mental state and perceived a pattern of information with a content leading to trigger sensory-motor and cognitive operation. Each pattern of information can arise at whatever moment of the interaction with the door.

\section{INSERT FIGURE 4}

Moreover, the HTA analysis separates high cognitive operations (e.g. "make decision" or "evaluate situational factors") from sensory-motor operations (e.g. "approach", "detect door"). However, it is clear that high cognitive and sensory-motor processes are performed in parallel during a skilled activity (Hoc and Amalberti, 1995). Parallelism is included in the TMTA.

Finally, the HTA depicted a procedure of door use without highlighting the possible degraded situations. To access to these situations, the analyst must realise an additional query about each step of the HTA model; like "Are devices visible to operator?" for the HTA step "4.1.Operate locking device" (figure 4). As we see above, the TMTA allows for eliciting degraded situations based on hidden or false affordances (Gaver, 1991), or on the sequence of 
operations through unexpected feed-backs detected during the task. The TMTA bring the possibility to simulate degraded situation, which constitutes a significant support for the analyst.

\section{Discussion}

TMTA is a new manner to apprehend task. Patterns of information specifying affordances coming from the work domain and perceived by an agent are described in priority. It provides support for coping with previously unanticipated combinations of information coming from the work domain.

\subsection{The contextual approach of task analysis embedded in TMTA}

Our study suggests that HTA, like the Rasmussen's decision ladder, is a sequential task model, whereas TMTA is a contextual one. But, one can argue that in the door use example, the model used was elementary, with a simple sequential plan ("Plan 0: Do 1-5 in order"). HTA analysis can be more complex, involving plans with logical loops triggered conditions satisfied in the environment (Stanton, 2006). These conditional plans can potentially represent task constraints coming from the context of work. Nevertheless, a fundamental difference between the TMTA and HTA approaches is their theoretical bases. HTA is based on "goal-directed behaviour comprising a sub-goal hierarchy linked by plans" (Stanton, 2006, p.58). TMTA is based on affordance-directed behaviour comprising information patterns coming from the work domain and triggering sensory-motor and cognitive operations, in order to achieve a general goal. This fundamental difference means that the HTA analyst looks for conditions that may trigger goals and sub-goals, whereas TMTA analyst looks for cognitive and sensory-motor operations allowing to control information coming from the work domain. Specifically, TMTA processes the contextual constraints described in the Work Domain Analysis as input to produce task constraints as output.

The importance of the context in task analysis has already been underlined through methods, like the Critical Decision Method (CDM - Klein and Armstrong, 2004). This technique is based on the construction of a timeline of an accident. Once the analyst has an 
understanding of the incident, key phases or decision points are highlighted. A set of probes about goals, cue identification, expectancy, situation assessment etc. are used to query workers about the factors explaining these phases or decision points. The drawback of this method is that it qualifies the selected situation as critical from a normative point of view: the negative output produced by the accidental situation. Moreover, it is a post-hoc analysis that is not easily usable for designing of a new work system. Finally, this method does not aim at being exhaustive. It rather develops the qualitative analysis of several particular work situations.

Rather than relying on an analysis of strategies and knowledge effectively involved in the activity of an agent, the contextual approach in task analysis relies on the idea that the work domain requires different kinds of strategies and knowledge more or less available to the agent. Thus, Sturrock and Kirwan (1996) propose to map various prior types of knowledge with corresponding degraded circumstances of work, in order to improve the information displayed on interface. This approach is close to the mental navigation in the $\mathrm{AH}$ and $\mathrm{PWH}$ proposed in TMTA. Nevertheless, the Type Of Knowledge Analysis (TOKA - Sturrock and Kirwan, 1996) differs from TMTA mainly by the fact that TOKA does not integrate the dynamic effects of sensory-motor movement and transformation made simultaneously by the agent on the work domain.

In the domain of Human Error Identification (HEI), research pointed out the necessity to consider the dynamic and sensory-motor interaction between humans and devices (Stanton et Baber, 1996). The human-machine interaction is analysed as a cycle of operations creating a context for task performance and associated degraded situations. A major technique in this area is TAFEI (Task Analysis For Error Identification, Baber and Stanton, 1996; Stanton and Baber, 1996). TAFEI produced task-based scenarios by mapping human activity onto machine states. Three methodological components allow this mapping: Hierarchical Task Analysis to model the human activity, State-Space Diagram to model the machine states and Transition Matrices to describe the interaction between the two former models. This mapping leads to extract legal (normal) and illegal (degraded) transitions in the transition matrices. 
Like TMTA, TAFEI gives the possibility to simulate scenarios of tasks and then offers predictions on degraded situations of work. These situations are the result of the sequence of interaction between the state of the operator activity and the state of work environment. Nevertheless, TAFEI inherits drawback associated to the Hierarchical Task Analysis technique that we have already noticed. The legal and illegal transitions that can emerge from a TAFEI analysis are conditioned by the normative procedure described through the Hierarchical Task Analysis technique.

More fundamentally, TAFEI analyses the interaction between a user and a particular machine, but not the interaction between a user and a domain of work. Work domain Analysis on which is based TMTA allows for describing an overall scope on which an agent can apply a general goal. For instance in the example of door task analysis, the domain of work can be concretely implemented through a lot of devices that satisfy the domain functions, like a car park barrier or a window through which the agent can eventually leave. The domain-based task analysis of TMTA provides the analyst with the possibility to analyse user interaction very early in the design process, as soon as the functions specifying the work domain of the object under design are defined. An articulation between the TAFEI and TMTA approaches could be an interesting development.

\subsection{TMTA as a model of task in accordance with the Cognitive Work Analysis}

Some authors had already proposed new models to replace the decision ladder for task analysis in the framework of the Cognitive Work Analysis. Higgins (1998) proposed a model based on goal-action cycles taken from Action Theory. It allows for describing an activity, like scheduling, that can be driven by sub-goals that are not yet included in a pre-defined global goal imposing a specific sequence of work. A cyclic unit of activity processes a sub-goal. The achievement of a sub-goal allows for processing a higher sub-goal and so on until a general goal is achieved. Despite the fact that this model provides an insight on how to overcome the limit of the procedural approach embedded in the Rasmussen's ladder, it does not yield a deeper integration of ecological work constraints of the domain in the task modelling. 
Miller and Vicente (1998) suggested a better articulation between work domain and task analysis. They modelled the task through a goal oriented graph (Plan/Goal Graph technique, PGG) which integrates work domain information. The goals and the means-ends relationship defined in PGG correspond to "means-ends" links between functions defined in the domain. This approach is interesting but leads to a technical problem. The model does not differentiate between the agent's mental navigation through the domain knowledge and its action as such, performed in the environment.

CWA considers that respectively domain, task, strategies, socio-organisational aspects and operator's competencies are sets of constraints included in each other. The elicitation of domain and task constraints provides the analyst with the degrees of freedom still available for defined strategies, work organisation and workers' competencies required. The Turing Machine Task Analysis describes what can be done without consideration of how it can be done or by whom. The possibility to describe a task for which the number of human or automate agents and their respective roles are not defined, is in accordance with the CWA approach (Vicente, 1999).

\subsection{Perspectives and limits of the TMTA method}

Beside these contributions, the TMTA presents some difficulties in its application. The TMTA is a logical modelling requiring a particular effort of clear description of the task control, after completing a Work Domain Analysis which is also time-consuming. We applied the methodology to a basic and static domain. The study of systems with more complex structures and involving a strongly dynamic dimension must be conducted to judge the power of generalisation of this method. Rapidly, the exponential number of configurations to process could be a hindrance for task analysis.

Moreover, this method is very dependent on the possibility to decompose the domain in subsystems and components. This Part-Whole decomposition drives the definition of the relevant patterns of information. Tasks performed on an intentional domain, that is to say mainly driven by individual conceptual goals and not by the structure of devices seem a priori less easy to be described by this method (Hajdukiewicz et al., 1999; Wong, Sallis, and O'Hare, 
1998). As Bubb (2006) pointed out, Turing machine formalism fits the modelling of routine works dependant on skill triggering contexts. The fit will certainly be poorer for creative works that are less determined by the contingencies of the situation.

From a practical point of view, the definition of an actual technique for task analysis would require more precision on the manner to proceed. Two main points can be considered. Firstly, the information values that we attributed to each cell of the table describing the work domain are a simplification. In each cell of the AH/PWH matrix, more than only one function is often present. The scoring of each function would complicate the analysis, even though it is potentially possible. Secondly, the conditions determining the way the agent navigates in the Abstraction Hierarchy during the simulation of a task needs to be validated (top-down, stagnation or bottom-up navigation)

Nevertheless, we think that TMTA appears as a promising framework for task analysis. It seems able to model the concept of affordance-specifying information as an operational concept in ergonomics and cognitive engineering to deepen the understanding of situations of work. Moreover, this approach constitutes a methodological bridge between CWA and ecological psychology (Gibson, 1979; Gibson, 2003).

\section{Acknowledgments}

We wish to thank Heiner Bubb and Erik Hollnagel for their helpful comments.

\section{References}

Annett, J., 2004. Hierarchircal Task Analysis. In N. A. Stanton, A. Hedge, K. Brookhuis, E. Salas and H. Hendrick (eds), Handbook of Human Factors and Ergonomics Methods. Boca Raton : CRC Press, 33-1-33-7.

Baber, C. and Stanton, N. A., 1996. Human error identification techniques applied to public technology: predictions compared with observed use. Applied Ergonomics, 27(2), 119-131. Baindbridge, L., 1997. The change in concepts needed to account for human behavior in complex dynamic tasks. IEEE Transactions on Systems, Man, and Cybernetics, 27(3), 351-359. 
Bubb B., 2006. A consideration of the nature of work and the consequences for the humanoriented design of production and products. Applied Ergonomics, 37, 401-407.

Burns, C. M. and Hajdukiewicz J. R., 2004. Ecological Interface Design. Boca Raton : CRC Press.

Chang, S-K and Drury C. G., 2007. Task demands and human capabilities in door use. Applied Ergonomics, 38, 325-335.

De Oliveira W. R., De Souto M. C. P., and Ludermir, T. B., 2001. Agent-Environment approach to the simulation of Turing Machines by neural networks. Proceedings of International Joint Conference on Neural Networks, $I J C N N^{\prime} 01,1,71-76$, Washington, USA.

Dominguez, C. O., 1997. First, do no harm: expertise and metacognition in laparoscopic surgery. Thesis (PhD). Wright State University, USA.

Gibson, J. J., 1979. The Ecological Approach to Visual Perception. London: Lawrence Erlbaum Associates.

Gibson, E. J., 2003. The world is so full of a number of things: on specification and perceptual learning. Ecological Psychology, 15, 283-287.

Gaver, W. W., 1991. Technology affordances, CHI'91 Conference Proceedings, 79-84.

Hajdukiewicz, J. R., Burns, C. M., Vicente, K. J., and Eggleston, R. G., 1999. Work Domain Analysis for intentional systems. 43rd Human Factors and Ergonomics Society Annual Meeting, Houston, 333-337.

Hajdukiewicz, J. R. and Vicente, K. J., 2004. A theoretical note on the relationship between work domain analysis and task analysis. Theoretical Issues in Ergonomics Science, 5, 527-538. Hoc, J.M., and Amalberti, R., 1995. Diagnosis: Some theoretical questions raised by applied research. Current Psychology of Cognition, 14, 73-101

Higgins, P. G., 1998. Extending cognitive work analysis to manufacturing scheduling. Proceedings of Computer Human Interaction Conference, 236-243 
Kieras, D., 1997. A guide to GOMS model usability evaluation using NGOMSL. In M.

Helander, T.K. Landauer, P. Prabhu (eds). Handbook of Human Computer Interaction. Elsevier.

Klein, G. and Armstrong, A. A., 2004. Critical Decision method. In N. A. Stanton, A. Hedge, K Brookhuis, E. Salas and H. Hendrick (eds). Handbook of Human Factors and Ergonomics Methods, Boca Raton : CRC Press, 58-1-58-6.

McGrenere J. and Ho W., 2000. Affordances: clarifying and evolving concept. Proceedings of Graphics Interface., Montrea, Canada.

Miller, C. A., and Vicente, K. J., 1998. Toward an integration of task and work domain analysis techniques for human-computer interface design. Proceedings of the 42nd Annual Meeting of the Human Factors and Ergonomics Society.

Miller, C. A., and Vicente, K. J., 2001. Comparison of display requirements generated via Hierarchical Task and Abstraction-Decomposition Space analysis techniques. International Journal of Cognitive Ergonomics, 5, 335-355.

Morineau, T., and Frénod, E., 2005. La modélisation du concept d'affordance à travers le formalisme des Machines de Turing, Congrès de la Société Française de Psychologie, Nancy, France.

Norman, D. A., 1988. The psychology of Everyday Things. New-York: Basic Books Inc.

Naikar, N., 2006, Beyond interface design: further applications of cognitive work analysis International Journal of Industrial Ergonomics, 36, 423-438.

Rasmussen, J., 1986. Information processing and human-machine interaction: An approach to cognitive engineering. New York: North-Holland

Rasmussen, J., Pejtersen, A. M., Goodstein, L. P., 1994. Cognitive systems engineering. New York: Wiley \& Sons.

Sheperd, A., 2001. Hierarchical Task Analysis. London : Taylor \& Francis.

Stanton, N., and Baber, C., 1996. A systems approach to human error identification. Safety Science, $22(1-3), 215-228$. 
Stanton N.A, Salmon P.M., Walker G.H., Baber Ch., and Jenkins D.P., 2005. Human factors methods. A practical guide for engineering and design. Aldershot: Ashgate.

Stanton, N., 2006. Hierarchical task analysis: Developments, applications, and extensions. Applied Ergonomics, 37, 55-19.

Sturrock, F., and Kirwan, B., 1996. Mapping knowledge utilisation by nuclear power plant operators in complex scenarios. In S.A. Robertson (ed). Contemporary Ergonomics. London: Taylor \& Francis, 165-171.

Suchman L.A., 1987. Plans and Situated Actions. The Problem of Human-Machine Communication. Cambridge University Press.

Turing A. M., 1936. On computable numbers, with an application to the Entscheidungsproblem, Proc. Lond. Math. Soc. 42(2), 230-265.

Turing A. M., 1937. On computable numbers, with an application to the Entscheidungsproblem. A correction. Proc. Lond. Math. Soc. 43(2), 544-546.

Vicente, K. J., 1999. Cognitive Work Analysis, toward safe, productive and healthy computerbased work. Mahwah NJ: Erlbaum.

Vicente, K. J., 2002. Ecological interface design: process and challenges. Human Factors, 44, $62-78$.

Vicente, K. J., Christoffersen, K., and Pereklita, A., 1995. Supporting operator problem solving through Ecological Interface Design. IEEE Transactions on Systems, Man, and Cybernetics, 25, $529-545$.

Vicente, K. J. and Rasmussen, J., 1990. The ecology of human-machine systems II: Mediating "direct perception" in complex work domains, Ecological Psychology, 2, 207-250.

Wells, A. J., 1998. Turing's analysis of computation and theories of cognitive architecture. Cognitive Science, 22, 269-294.Wells, A. J., 2002. Gibson's affordances and Turing's theory of computation. Ecological Psychology, 14(3), 141-180. 
Wong, W.B.L., Sallis P.J., and O'Hare D., 1998. The Ecological Approach to Interface Design: Applying the Abstraction Hierarchy to Intentional Domains. OZCHI, Australasian Computer Human Interaction Conference, 144.

\begin{abstract}
About the authors
Thierry Morineau received a PhD (1996) in Psychology at the University of Angers. He is currently Senior Lecturer at the University of Southern Brittany (LESTIC team of CRPCC laboratory). His research endeavours to deepen the cognitive engineering approach and its relationship with ecological psychology.
\end{abstract}

Emmanuel Frénod received a $\mathrm{PhD}$ (1994) in Mathematics at the University of Paris 13 and an HDR (1999) in Mathematics and Applications at the University of South Brittany. He is Professor at the University of Southern Brittany (Lab-STICC). His current research concerns modelling complex systems and pde analysis.

Caroline Blanche received a Master (2003) in Psychology at the University of Rennes II. She currently prepares a $\mathrm{PhD}$ in Psychology at the University of South Brittany (LESTIC team of CRPCC laboratory). Her current research concerns the application of cognitive engineering to improve an information system.

Laurence Tobin received a PHD in applied linguistics from the University of Paris V. She has taught in universities in Scotland, New Zealand and France. Currently a senior lecturer at the University of Southern Brittany, her research interests are in the field of non-verbal communication, computer mediated communication and ecological psychology. 
Table 1: An example of degraded patterns of information coming from a nuclear plant flow system

(Information value $=0$ means that the subsystem is closed, Information value $=1$, the subsystem is open)

\begin{tabular}{|c|c|c|}
\hline$\frac{\text { Water Network }}{\text { System }}$ & $\begin{array}{c}\text { Valve } \\
\text { Subsystem }\end{array}$ & $\frac{\text { Valve Command }}{\text { component }}$ \\
\hline 1 & 0 & 0 \\
\hline
\end{tabular}


Table 2: A General Work Domain analysis of a door system

\begin{tabular}{|c|c|c|c|c|}
\hline & $\begin{array}{c}\text { Door } \\
\text { System }\end{array}$ & \begin{tabular}{|c} 
Leaf \\
subsystem
\end{tabular} & $\begin{array}{c}\text { Locking } \\
\text { component }\end{array}$ & Handle component \\
\hline $\begin{array}{l}\text { Functional } \\
\text { Purpose }\end{array}$ & $\begin{array}{l}\S \text { Closes } \\
\text { and opens } \\
\text { an entry }\end{array}$ & $\begin{array}{l}\text { revents direct access } \\
\text { revents air and substance } \\
\text { exchanges }\end{array}$ & $\S$ Controls access & $\S$ Facilitates access \\
\hline $\begin{array}{l}\text { Abstract } \\
\text { Function }\end{array}$ & & $\begin{array}{l}\S \text { Physical forces } \\
\S \text { Mechanical and/or } \\
\text { automatical laws of door } \\
\text { action and control } \\
\S \text { Laws of entropy }\end{array}$ & $\begin{array}{l}\S \text { Physical forces } \\
\S \text { Mechanical and/or } \\
\text { automatical laws of door } \\
\text { action and control } \\
\S \text { Material or data coding } \\
\text { and detection laws }\end{array}$ & $\begin{array}{l}\S \text { Physical forces } \\
\S \text { Mechanical and/or } \\
\text { automatical laws of door } \\
\text { action and control } \\
\S \text { Ergonomic principles }\end{array}$ \\
\hline Process & & $\begin{array}{l}\S \text { Operating process } \\
\S \text { Movement direction } \\
\S \text { Force required to } \\
\text { operate } \\
\S \text { Isolation process of } \\
\text { building materials }\end{array}$ & $\begin{array}{l}\text { § Operating process } \\
\S \text { Movement direction } \\
\S \text { Force required to } \\
\text { operate } \\
\S \text { Material or data coding } \\
\text { process }\end{array}$ & $\begin{array}{l}\text { § Operating process } \\
\S \text { Movement direction } \\
\text { § Force required to } \\
\text { operate } \\
\S \text { Handle command and } \\
\text { control processes }\end{array}$ \\
\hline $\begin{array}{l}\text { Physical } \\
\text { Function }\end{array}$ & & $\begin{array}{l}\S \text { Equipment of action } \\
\text { power } \\
\S \text { Door features } \\
\text { (dimensions, weight,...) } \\
\S \text { Isolation equipment }\end{array}$ & $\begin{array}{l}\text { § Equipment of action } \\
\text { power } \\
\S \text { Lock features } \\
\S \text { Control-Command } \\
\text { equipment }\end{array}$ & $\begin{array}{l}\S \text { Equipment of action } \\
\text { power } \\
\S \text { Handle features } \\
\S \text { Control-Command } \\
\text { equipment }\end{array}$ \\
\hline $\begin{array}{l}\text { Physical } \\
\text { Form }\end{array}$ & & $\begin{array}{l}\S \text { Location and } \\
\text { appearance }\end{array}$ & $\begin{array}{l}\S \text { Location and } \\
\text { appearance }\end{array}$ & $\begin{array}{l}\S \text { Location and } \\
\text { appearance }\end{array}$ \\
\hline
\end{tabular}


Table 3: Examples of possible meanings coming from the perception of

patterns of information in the work domain.

Degraded situation requires the agent to change mental state

and consequently navigate into the Abstraction Hierarchy of the domain.

\begin{tabular}{|c|c|c|c|c|c|}
\hline & \multicolumn{3}{|c|}{$\begin{array}{c}\text { Information coming from } \\
\text { Work Domain }\end{array}$} & \multicolumn{2}{|r|}{ Possible meanings } \\
\hline $\begin{array}{l}\text { information } \\
\text { Pattern }\end{array}$ & $\begin{array}{c}\text { Leaf } \\
\text { Subsystem }\end{array}$ & $\begin{array}{l}\text { Locking } \\
\text { Component }\end{array}$ & $\begin{array}{l}\text { Handle } \\
\text { Component }\end{array}$ & $\begin{array}{l}\text { Normal } \\
\text { Situation }\end{array}$ & $\begin{array}{c}\text { Degraded } \\
\text { Situation }\end{array}$ \\
\hline SO & $\#$ & \# & $\#$ & $\begin{array}{l}\S . \text { The agent } \\
\text { completes the } \\
\text { task }\end{array}$ & $\begin{array}{l}\text { §. The door cannot be found by the } \\
\text { agent (Physical form). } \\
\text { §. The door is hidden by other objects } \\
\text { (no relevant information is available to } \\
\text { achieve the task directly). } \\
\text { (Physical form). } \\
\text { §. Complete lack of understanding of } \\
\text { the door system (Abstract Function). } \\
\text { \$. Mental overload (all levels). }\end{array}$ \\
\hline$S 1$ & \# & 0 & $\#$ & $\begin{array}{l}\S \text {. The agent is } \\
\text { in front of the } \\
\text { door }\end{array}$ & $\begin{array}{l}\S \text {. No operation on the door components } \\
\text { is effective (Process). }\end{array}$ \\
\hline$S 2$ & 0 & 0 & 1 & $\begin{array}{l}\S \text {. The agent } \\
\text { moves the } \\
\text { handle and has } \\
\text { to unlock the } \\
\text { door. }\end{array}$ & $\begin{array}{l}\text { \$. The agent does not succeed in } \\
\text { transforming the state of the lock } \\
\text { (Physical function, Process). }\end{array}$ \\
\hline$S 3$ & 0 & 1 & 0 & $\begin{array}{l}\S \text {. The agent has } \\
\text { to move the } \\
\text { handle and the } \\
\text { lock is still } \\
\text { open. }\end{array}$ & $\begin{array}{l}\S \text {. The handle cannot be manipulated by } \\
\text { the agent (Physical function). } \\
\S \text {. The handle is broken (Physical } \\
\text { function, Process). }\end{array}$ \\
\hline$S 4$ & 0 & 1 & 1 & $\begin{array}{l}\S \text {. The leaf will } \\
\text { be opened in a } \\
\text { couple of } \\
\text { seconds. }\end{array}$ & $\begin{array}{l}\S . \text { The leaf is barred by something that } \\
\text { cannot be perceived (Process). } \\
\S . \text { Wood swelling (Process). }\end{array}$ \\
\hline$S 5$ & 1 & 0 & 0 & - & $\begin{array}{l}\S \text {. The leaf is still open whilst the lock } \\
\text { and the handle are in a close state (lock } \\
\text { notched in the void, handle barred in } \\
\text { close state) (Physical form) } \\
\S \text {. False information about the leaf } \\
\text { subsystem }\end{array}$ \\
\hline S6 & 1 & 1 & 0 & - & $\begin{array}{l}\S \text {. The handle is broken and stays in } \\
\text { close state (Physical function, Process). } \\
\S \text {. False information about the handle } \\
\text { component (Physical form) }\end{array}$ \\
\hline$S 7$ & 1 & 0 & 1 & - & $\begin{array}{l}\text { §. The lock is notched in the void. } \\
\text { Physical form) } \\
\S \text {. False information about the locking } \\
\text { component (Physical form) }\end{array}$ \\
\hline$S 8$ & 1 & 1 & 1 & $\begin{array}{l}\S . \text { The door } \\
\text { system is open. }\end{array}$ & $\begin{array}{l}\S . \text { The door system stands open, despite } \\
\text { its requirement to filter exchanges. } \\
\text { (Physical form) }\end{array}$ \\
\hline
\end{tabular}

Legend: The symbol 0 means information relevant for the task but not satisfying the task goal. The symbol 1 means information relevant for the task and satisfying the task goal. The symbol \# means a lack of information perceived as relevant for the task. In italics, the AH levels typically involved in the perception of degraded situations are shown. 
Table 4: An example of opening task sequence with a pushing door and a handle apparently affording a pull action scheme (see figure 3 ).

\begin{tabular}{|c|c|c|c|c|c|c|c|}
\hline $\begin{array}{c}\text { Task } \\
\text { Stage }\end{array}$ & $\begin{array}{c}\text { Leaf } \\
\text { subsystem }\end{array}$ & $\begin{array}{c}\text { Locking } \\
\text { Component }\end{array}$ & $\begin{array}{c}\text { Handle } \\
\text { Component }\end{array}$ & $\begin{array}{l}\text { Transfor- } \\
\text { mation }\end{array}$ & $\begin{array}{c}\text { Current } \\
\text { Mental } \\
\text { State }\end{array}$ & $\begin{array}{c}\text { Next mental } \\
\text { state }\end{array}$ & Movement \\
\hline $\begin{array}{c}\text { Stage } \\
1\end{array}$ & 0 & 0 & 0 & - & $\begin{array}{c}\text { Physical } \\
\text { Forms }\end{array}$ & $\begin{array}{c}\text { Physical } \\
\text { Forms } \\
\text { Where and } \\
\text { what are the } \\
\text { components of } \\
\text { door? }\end{array}$ & Approach \\
\hline $\begin{array}{c}\text { Stage } \\
2\end{array}$ & 0 & 0 & 0 & $\begin{array}{l}\text { turns the } \\
\text { key }\end{array}$ & $\begin{array}{c}\text { Physical } \\
\text { Forms }\end{array}$ & $\begin{array}{c}\text { Physical } \\
\text { Functions } \\
\text { The key will } \\
\text { work? }\end{array}$ & $\begin{array}{l}\text { Hand } \\
\text { rotation }\end{array}$ \\
\hline $\begin{array}{c}\text { Stage } \\
3\end{array}$ & 0 & 1 & 0 & - & $\begin{array}{l}\text { Physical } \\
\text { Functions }\end{array}$ & $\begin{array}{c}\text { Physical } \\
\text { Functions } \\
\text { The handle } \\
\text { will work? }\end{array}$ & $\begin{array}{l}\text { Pulls on the } \\
\text { handle }\end{array}$ \\
\hline $\begin{array}{c}\text { Stage } \\
4\end{array}$ & 0 & 1 & 0 & - & $\begin{array}{l}\text { Physical } \\
\text { Functions }\end{array}$ & $\begin{array}{l}\text { Processes } \\
\text { Effort } \\
\text { generated } \\
\text { enough? }\end{array}$ & $\begin{array}{l}\text { Pulls on the } \\
\text { handle more } \\
\text { strongly }\end{array}$ \\
\hline $\begin{array}{c}\text { Stage } \\
5\end{array}$ & 0 & 1 & 0 & - & Processes & $\begin{array}{l}\text { Abstract } \\
\text { Functions } \\
\text { Is it the right } \\
\text { law of handle } \\
\text { functioning? }\end{array}$ & $\begin{array}{l}\text { Pushes on } \\
\text { the handle }\end{array}$ \\
\hline $\begin{array}{c}\text { Stage } \\
6\end{array}$ & 0 & 1 & 1 & - & $\begin{array}{c}\text { Abstract } \\
\text { Functions }\end{array}$ & $\begin{array}{l}\text { Abstract } \\
\text { Functions } \\
\text { The leaf } \\
\text { functioning } \\
\text { follows the } \\
\text { handle } \\
\text { functioning? }\end{array}$ & $\begin{array}{l}\text { Pushes on } \\
\text { the leaf via } \\
\text { the handle }\end{array}$ \\
\hline $\begin{array}{c}\text { Stage } \\
7\end{array}$ & 1 & 1 & 1 & - & $\begin{array}{c}\text { Abstract } \\
\text { Functions }\end{array}$ & $\begin{array}{c}\mathrm{H} \\
\text { What else? }\end{array}$ & $\begin{array}{c}\text { Goes } \\
\text { through the } \\
\text { doorway }\end{array}$ \\
\hline
\end{tabular}


Figure 1. The decision ladder proposed by Rasmussen (1986)

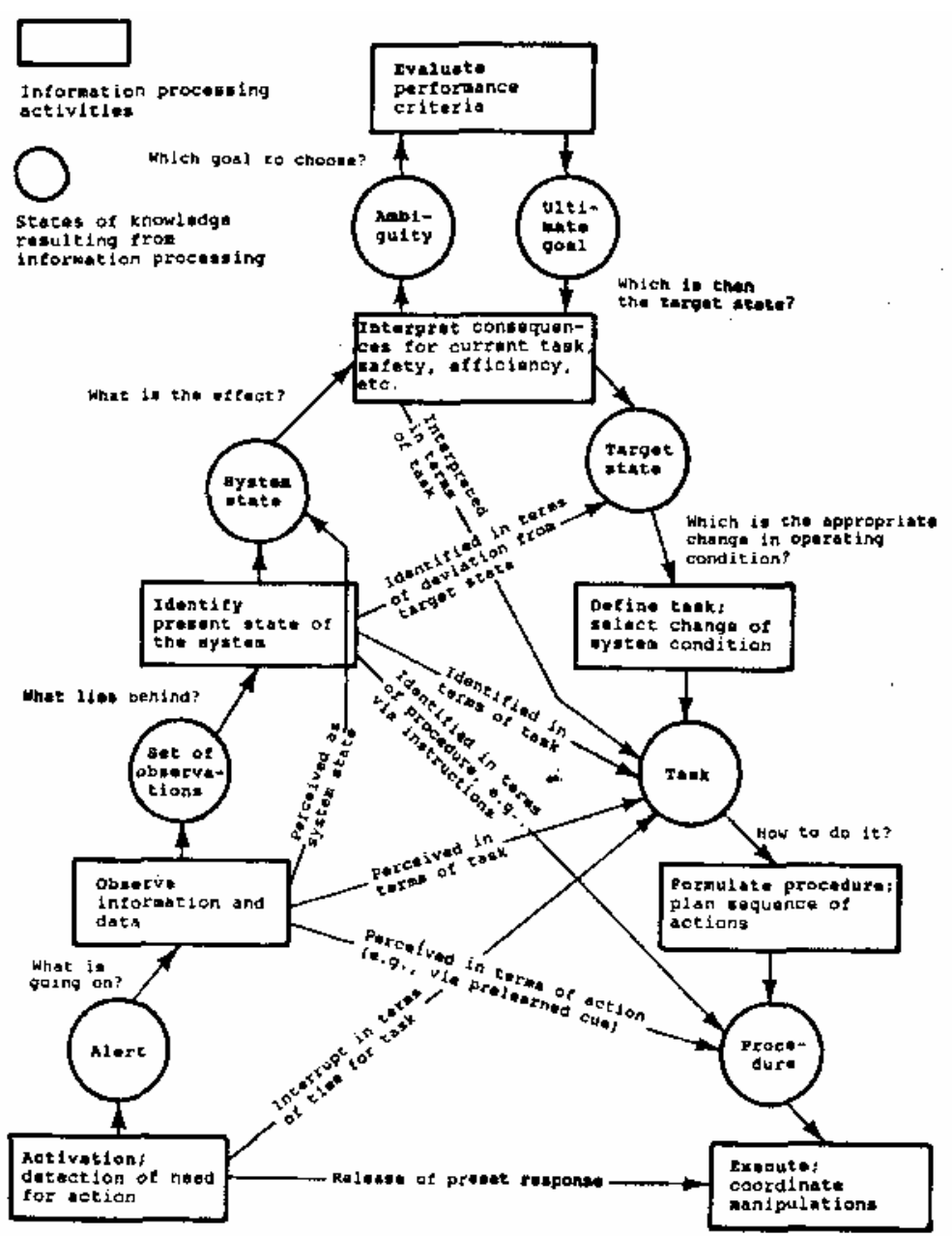


Figure 2. Articulation between the Turing Machine processing control task and AbstractionDecomposition Space describing the Work Domain.

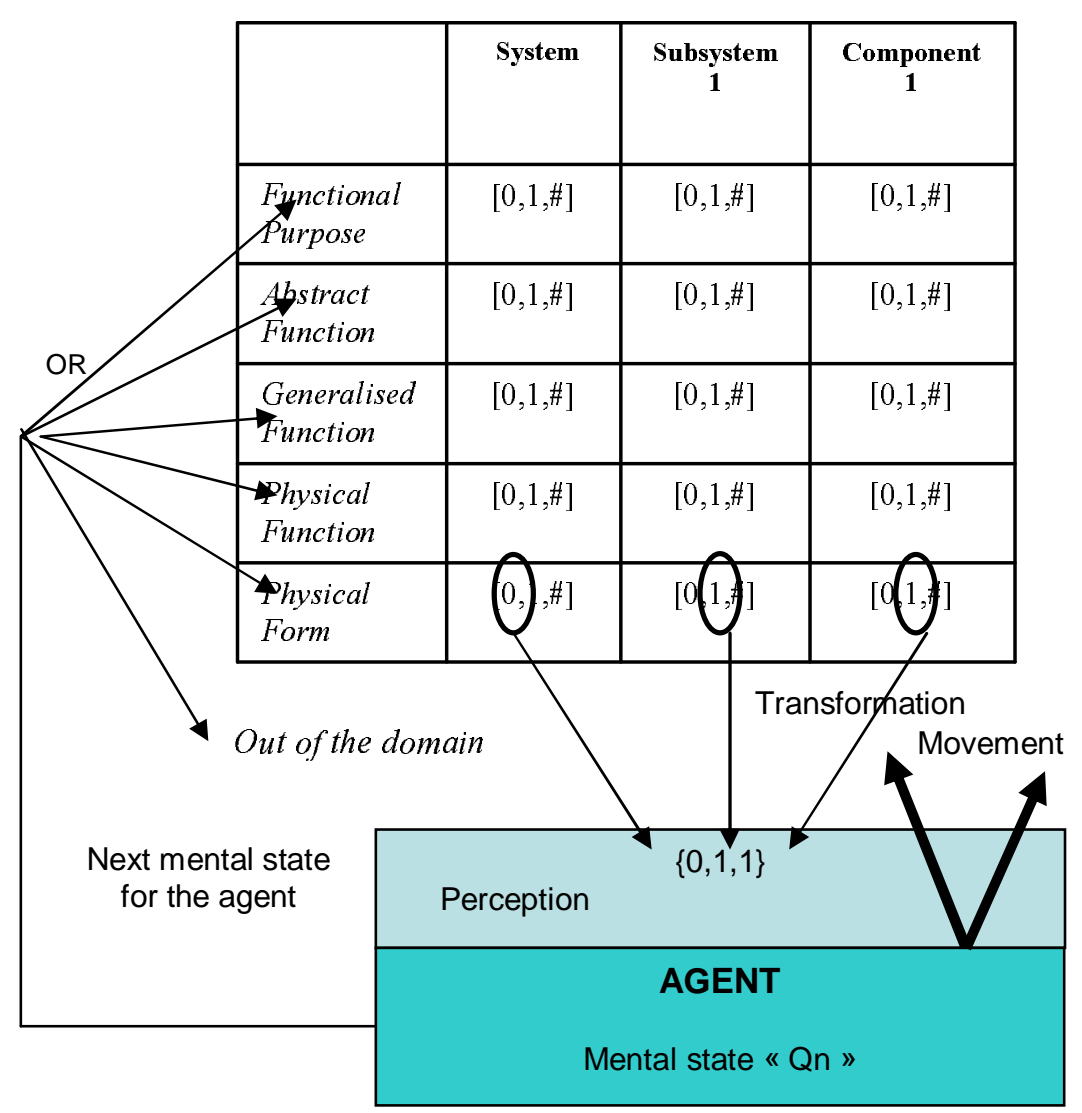


Figure 3. An example of door suggesting a pull action scheme

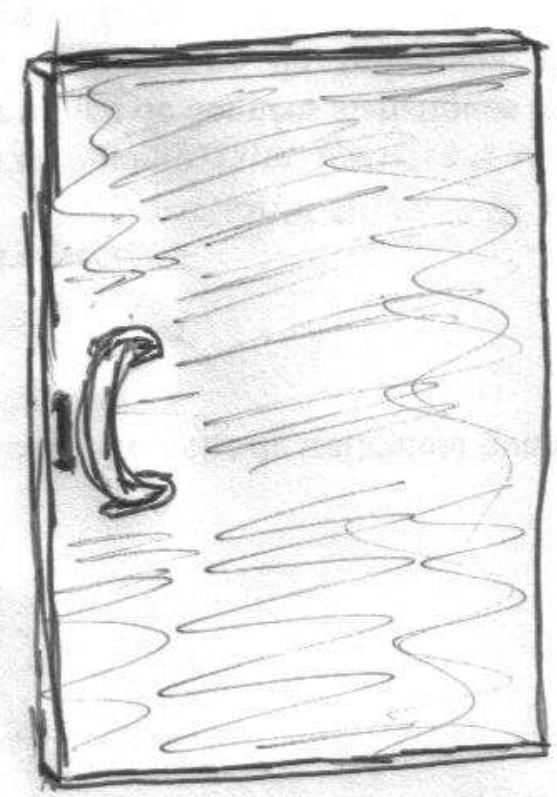


Figure 4: The Hierachical Task Analysis of the door system proposed by Chang and Drury (2007)

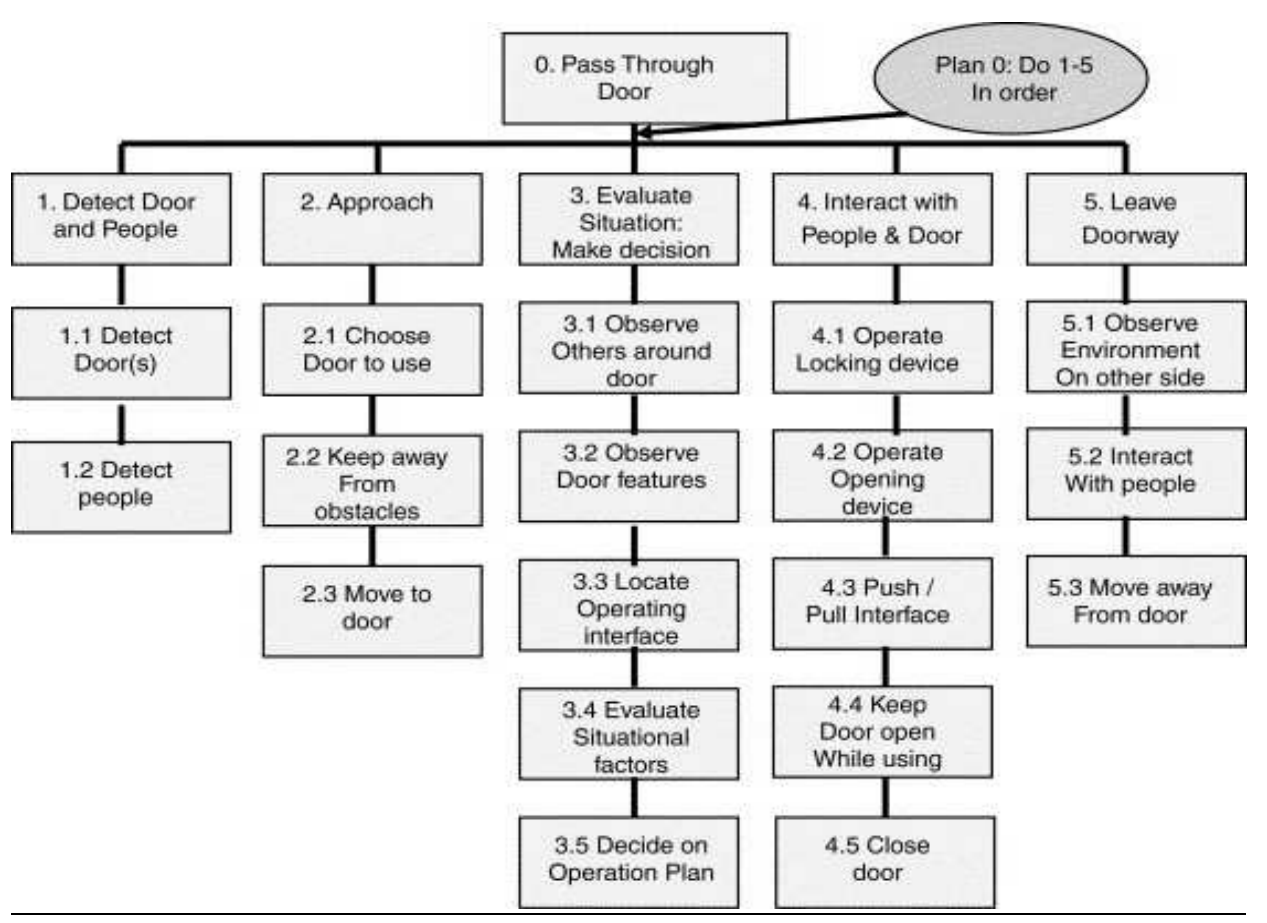

